Article

\title{
Evaluation of the Sustainable Coupling Coordination of the Logistics Industry and the Manufacturing Industry in the Yangtze River Economic Belt
}

\author{
Ying Gong ${ }^{1,2}$, Xiao-Qiong Yang ${ }^{3}$, Chun-Yan Ran ${ }^{4}$, Victor Shi ${ }^{5}$ and Yu-Feng Zhou ${ }^{6, *}$ \\ 1 China Institute of FTZ Supply Chain, Shanghai Maritime University, Shanghai 201306, China; \\ cqgongying@ctbu.edu.cn \\ 2 Chongqing Engineering Research Center for Processing, Storage and Transportation of Characterized \\ Agro-Products, Chongqing Technology and Business University, Chongqing 400067, China \\ 3 School of Foreign Languages, Chongqing Technology and Business University, Chongqing 400067, China; \\ yangxiaoqiong@ctbu.edu.cn \\ 4 Dongfang Electric Machinery CO., LTD, Deyang 200240, China; ran8983@foxmail.com \\ 5 Lazaridis School of Business and Economics, Wilfrid Laurier University, 75 University Avenue West, \\ Waterloo, ON N2L 3C5, Canada; cshi@wlu.ca \\ 6 Chongqing Engineering Technology Research Center for Information Management in Development, \\ Chongqing Technology and Business University, Chongqing 400067, China \\ * Correspondence: xtuzyf@email.ctbu.edu.cn; Tel.: +86-152-2311-5578
}

\section{check for} updates

Citation: Gong, Y.; Yang, X.-Q.; Ran, C.-Y.; Shi, V.; Zhou, Y.-F. Evaluation of the Sustainable Coupling Coordination of the Logistics Industry and the Manufacturing Industry in the Yangtze River Economic Belt. Sustainability 2021, 13, 5167. https://doi.org/10.3390/ su13095167

Academic Editors: Yuvraj Gajpal and Julian Müller

Received: 2 March 2021

Accepted: 21 April 2021

Published: 5 May 2021

Publisher's Note: MDPI stays neutral with regard to jurisdictional claims in published maps and institutional affiliations.

Copyright: (C) 2021 by the authors Licensee MDPI, Basel, Switzerland. This article is an open access article distributed under the terms and conditions of the Creative Commons Attribution (CC BY) license (https:/ / creativecommons.org/licenses/by/ $4.0 /)$.

\begin{abstract}
In order to promote the sustainable and coordinated development of the logistics industry and the manufacturing industry in the Yangtze River Economic Belt of China and provide the policy makers with decision-making references, this paper explored the spatio-temporal evolution of the coupling coordination development level of the two industries. A three-stage super-efficiency SBM model, which eliminated the influence of environmental factors and random errors, was constructed to make it possible to conduct an in-depth comparative analysis on the effective decision-making units (DMUs), making the calculation results more accurate. This was the main contribution of this paper. Based on the new model considering undesirable output, this paper analyzed the panel data of 11 provinces and cities in the Yangtze River Economic Belt from 2007 to 2017 and investigated the coordination development level from the dimensions of time and space considering the energy input and carbon emissions of the two industries. Our main research findings were as follows. First, due to the relative lagging of the logistics industry in promoting the development of the manufacturing industry, the overall level of the coordination between the two industries was at a stage of limited coordination. Second, the regional differences were significant with a spatial evolution pattern of "high in the east and low in the west". Third, environmental factors affected the input efficiency of the logistics industry and the manufacturing industry, especially the latter. Overall, this paper made theoretical and practical contributions to promoting the joint development of the two industries, improving the logistics industry and upgrading the manufacturing industry.
\end{abstract}

Keywords: logistics; manufacturing; sustainable development; coupling coordination; Yangtze River Economic Belt; three-stage super-efficiency SBM model

\section{Introduction}

The Yangtze River Economic Belt (YREB) is important for China to integrate the east and the west, unlock the north and the south, and connect the land and the sea. With $40 \%$ of the country's population and $44.1 \%$ of the total economic volume [1], it is one of the most important industrial corridors in China. Now, the manufacturing industry (MI) in YREB has entered an important development stage of transformation and upgrading. Advanced MI is the symbol of high-quality development in YREB, and is also the regional foundation for competitiveness and innovativeness. Furthermore, as a critical and strategic industry 
which supports the development of the national economy, the logistics industry (LI) plays a valuable role in improving and upgrading of the MI in YREB [2]. Hence, promoting the coordinated development of the logistics industry and the manufacturing industry (LIMI) is of great strategic value for transforming the mode of economic growth and optimizing the industrial structure $[3,4]$.

There are a lot of studies on the coupling relationship between LIMI and their evaluations [5-9]. However, from the perspective of spatio-temporal evolution, eliminating environmental factors and random errors, little research has been conducted on the evaluation of the coupling coordination (CC) between the two industries, especially on the empirical research on YREB. Therefore, this paper takes YREB as the subject, adopts the three-stage super-efficiency SBM model and data envelopment analysis (DEA) CC Evaluation Model to evaluate and measure YREB's CC development level between LIMI, and analyzes the CC development level's spatio-temporal evolution from the regional and provincial levels. Compared with the methods proposed in the literature, our three-stage super-efficiency SBM model in this research eliminated the environmental factors and random errors. This made it possible to conduct an in-depth comparative analysis on the effectiveness of decision-making units (DMUs). Moreover, it means that results could more accurately and truly reflect YREB's CC development level and its regional distribution differences.

In addition, China is a country with a huge amount of $\mathrm{CO} 2$ emission, facing the increasing pressure of energy conservation and emission reduction. Controlling carbon emissions and promoting sustainable development have become important policy objectives of the government $[10,11]$. Considering the green development in YREB, this paper took industrial energy consumption and carbon emissions into the indicator system and adopted a three-stage super-efficiency SBM model based on undesirable output [12]. This was done by eliminating the influence of environmental factors and random errors so that the results could better reflect the spatio-temporal differences of the CC development level between LIMI in different regions of YREB.

The natural resource endowment and development level of LIMI in YREB are different from those in other regions. Therefore, $\mathrm{CC}$ of the two industrial systems must have the specific characteristics of time and space.

This paper aimed at exploring the current situation and spatio-temporal evolution of CC development levels of LIMI in YREB in order to promote the sustainable and coordinated development of LIMI and the transformation and upgrading of MI, which could provide decision-making references for the government in developing the regional LIMI and offering suggestions on improving the coordination between LIMI.

The potential academic contributions of this paper are as follows. First, it constructed a three-stage super-efficiency SBM model to evaluate CC development levels between LIMI. This model eliminated the influence of environmental factors and random errors to make it possible to conduct an in-depth comparative analysis on the effectiveness of DMUs, making the calculation results more accurately and truly reflective of the CC development level. Second, taking YREB as the research object and quantitatively evaluating and measuring CC development levels between LIMI, this paper conducted an analysis on the spatiotemporal evolution characteristics of CC development from regional and provincial levels, and obtained corresponding policy implications.

This paper falls into six parts. The first part is the introduction, which mainly examines the research background and the main contributions of this paper. The second part is a literature review. The third part is the method which introduces the case background and the construction process of the evaluation model, including the selection of indicator variables, the source and processing of data, and the construction of the model. The fourth part is the empirical findings and analysis. The fifth part is the implications and the last part is the conclusions of this paper. 


\section{Literature Review}

There is a close relationship between LIMI. When the coordination is good, the logistics outsourcing has a positive impact on the performance of MI [13]. For example, Sohail et al. [14] conducted a survey on Malaysian enterprises and found that the third-party logistics service had a positive influence on the cost, strategic performance, and customer satisfaction of the client enterprises. Rahman (2011) [15] conducted a questionnaire on the logistics operation managers of 210 large enterprises in Australia, and found that the use of the third-party logistics had a positive impact on the internal logistics system performance of Australian enterprises. Khan [16] took Pakistan as an example to illustrate that the high-quality fusion and linkage between LIMI produces enormous economic benefits.

Some researchers have analyzed the coupling relationship between LIMI mainly from the perspectives of the supply-leading theory, demand-compliance theory, and interactionintegration theory. The supply-leading theory [17] maintains that LI is separated from MI and is the result of the development of MI to a certain stage; MI creates market demands for LI, while LI needs to rely on MI's development. According to the demandcompliance theory [5], the development of LI cultivates the core competitiveness for MI, and is the "third profit source" of MI. In recent years, the interaction-integration theory [6-9] has become the mainstream in the academic circles, which holds that a twoway interactive relationship of coordinated development and mutual promotion exists between LIMI. Namely, LI supports the development of MI and provides the driving force for its transformation and upgrading, while with higher requirements for the logistics service, MI facilitates the development of LI. Wang et al. [13] conducted a study on the interactive mechanism between LI efficiency and MI efficiency. Taking the three provinces in Northeast China and the Yangtze River Delta as the research area, they proved that the interaction between LI efficiency and MI efficiency was unequal in different economic development areas. Currently, most researchers in China take the provincial administrative region as the research object to explore the coupling coordination (CC) relationship between the two industries, but there is little literature from the perspective of regional coordination.

Other researchers have taken into consideration the influencing factors of evaluating CC development. Considering industrial input, output efficiency, development scale, and growth capability as the indicator system, Gong and Wang [18] conducted an empirical study on CC degree of LIMI from 2003 to 2013. Their results showed that the two industries have evolved gradually from imbalance to coordinated development. Shi [19] deems that the level of urbanization, technological progress, policy level, and human resource investment are the important factors affecting the coordinated development of the two industries. Shen [20] holds that important factors include the logistics service provider, system, and technological environment evolution. Chen et al. [21] divided the LIMI composite system into a manufacturing subsystem and logistics subsystem, and used 12 indicators such as manufacturing added value and freight volume to describe the coordinated linkage between the two industries. Tao [22] holds that industrial scale, industrial performance, social contributions, and development potentials are the four main factors affecting the coordinated development of the two industries.

Many models and methods can be used to research the CC between LIMI. In terms of the measures of the coordination degree between LIMI, researchers have adopted methods such as the coordination degree model of composite systems [23], gray correlation analysis [24,25], GRNN network model [26], hypernetwork analysis [27], spatio-temporal evolution method [21], and symbiotic matching configuration [28]. In terms of the measures of collaborative efficiency, the input-output method [29], DEA model, and improved super-efficiency DEA model [30] are the mainstream evaluation methods. The CC degree model judges the CC level based on the differences of the development of the system comprehensive level [31-33], which leaves a strong mark of subjective interference in the evaluation results. Tang [34] further points out that the combination of the CC degree model and the information entropy method is an effective way to evaluate the coupling relationship. DEA has the property of unit invariance, and its indicator weight is gener- 
ated by linear programming data, which is not subject to subjective interference and can more directly reveal the coupling relationship and more scientifically evaluate the relative effectiveness of coupling effects between LIMI, thus reflecting the CC development level between them [35]. Based on the traditional DEA model, the super-efficiency SBM model proposed by Tone [36] can effectively deal with the undesirable output, and can conduct a further comparative analysis on the effective decision-making units (DMUs).

Different from the previous studies, this paper adopted a three-stage super-efficiency SBM model which eliminated the influence of environmental factors and random errors on the system, and took YREB as the research object, making it possible to more accurately measure the spatio-temporal evolution of the CC development level of LIMI so as to provide decision-making references for the government to formulate policies.

\section{Method}

\subsection{Case Background}

Comprehensively promoting the high-quality development of YREB is a major strategy for China to shape its new development advantages, among which the coordination development of LIMI is a key point. In order to clarify the current situation of CC between LIMI in YREB, this paper answered the following questions: What is the status quo of CC of LIMI in different regions of YREB? Which industry is playing a leading role? At the provincial level, what are the spatio-temporal change characteristics of CC levels of the two industries? The answers to these questions are of great practical value to the YREB and the coordinated development of regional economy. Hence, this paper evaluated CC development levels through the input-output efficiency between LIMI, with an aim to reveal the complex relationship and status quo of $C C$ between the two industries more effectively and objectively. This in turn can provide managerial and policy insights for the government and industries.

\subsection{Proposed Steps}

\subsubsection{Indicator Variables Selecting}

Firstly, the input and output indicators should be selected. At present, China has not yet established an independent statistical system of LI. In this paper, the indicator data of the transportation industry, warehousing industry, and postal industry are used to replace the relevant indicators of LI. Based on the three dimensions of labor, capital, and energy, this paper constructed the input indicator system of LI [37,38]. Among them, the dimensions of capital input, labor input, and energy input took the fixed assets investment, the employees' average salaries, and the total energy consumption (converted into standard coal and then added up) of LI, respectively, as the input indicators. In terms of the output indicators, the freight volume and total output value in LI were the desirable outputs, and the LI carbon emissions were the undesirable outputs $[39,40]$.

The input indicators in MI also included three dimensions of capital, labor, and energy [41,42]. Among them, the dimensions of capital input, labor input, and energy input took the fixed assets investment, the employees' average salaries, and the total energy consumption (converted into standard coal and then added up) in MI, respectively, as input indicators. In terms of the output indicators, the total output value and the carbon emissions in MI were taken as the desirable output and the undesirable output, respectively $[37,43]$.

Then, the indicators of environment variables were selected. Environment variables are objective factors that affect input-output efficiency but are not within the controllable range of samples $[44,45]$. They do not change in the short periods but interfere with the evaluation effects of the DEA model, so their influence should be eliminated in the process of modeling. In this paper, the following environment variables were selected from influencing factors such as economy, policy, opening to the outside world, transportation, and urbanization $[37,46,47]$ : (1) The level of regional economic development was represented by the regional per capita GDP; (2) government support by the proportion of total regional 
fiscal expenditure to regional GDP; (3) the degree of regional opening-up the proportion of total regional import and export to regional GDP; (4) the density of transportation network by the ratio of the total regional mileage of railways, highways, and waterways to the regional area; (5) the level of scientific and technological innovation by the proportion of regional research and development expenditure to regional GDP; and (6) the urbanization rate was represented by the proportion of the regional urban resident population to the regional resident population.

\subsubsection{Data Processing}

Taking the eleven years (from 2007 to 2017) as the research period, this paper collected the indicator data of eleven provinces and cities in YREB to analyze the spatio-temporal evolution of CC development level of LIMI. The data mainly came from the China Statistical Yearbook, China Science and Technology Statistical Yearbook, China Population and Employment Statistical Yearbook, China Labor Statistics Yearbook, China Energy Statistical Yearbook, China Fixed Assets Statistical Yearbook, China Industrial Statistics Yearbook, and China Logistics Statistical Yearbook, as well as statistical yearbooks of each province and city.

In order to make the indicator data over the years comparable, this paper converted all data into constant prices based on the year of 2007, thus excluding the impact of price on economic indicators [48-50]. Moreover, following Song et al. [51], this paper converted the undesirable output indicator into the input indicator. The descriptive statistics of relevant indicators are shown in Table 1.

Table 1. Descriptive statistics of indicator variables of LIMI in YREB.

\begin{tabular}{cccccc}
\hline Variable & Observations & Minimum & Maximum & Mean & Standard Deviation \\
\hline Y1 (billion yuan) & 121 & 19.40 & 103.55 & 53.72 & 22.65 \\
Y2 (thousand yuan) & 121 & 17.77 & 102.19 & 41.70 & 15.91 \\
Y3 (thousand tons of SC) & 121 & 226.07 & $23,871.95$ & 9974.79 & 4725.72 \\
Y4 (billion yuan) & 121 & 25.26 & 767.47 & 194.03 & 187.46 \\
Y5 (thousand yuan) & 121 & 17.06 & 52.63 & 31.72 & 8.63 \\
Y6 (thousand tons of SC) & 121 & 4852.38 & $61,207.88$ & $24,633.28$ & $10,708.03$ \\
Y7 (thousand tons) & 121 & 267,870 & $4,342,975.77$ & $1,389,758.03$ & $766,094.40$ \\
Y8 (thousand tons of carbon) & 121 & 131.53 & $14,091.23$ & 6041.72 & 2854.06 \\
Y9 (thousand tons of carbon) & 121 & 5876.50 & $90,294.00$ & $35,358.46$ & $16,012.43$ \\
Y10 (billion yuan) & 121 & 16.44 & 202.24 & 69.72 & 38.97 \\
Y11 (billion yuan) & 121 & 97.89 & 2975.30 & 704.07 & 610.71 \\
\hline
\end{tabular}

Note: Y1 represents the fixed asset investment in LI; Y2 represents the employees' average salary in LI; Y3 represents the total energy consumption in LI; Y4 represents the fixed asset investment in MI; Y5 represents the employees' average salary in MI; Y6 represents the total energy consumption in MI; Y7 represents the freight volume; Y8 represents the total carbon emission in LI; Y9 represents the total industrial carbon emission; Y10 represents the total output value in LI; Y11 represents the total industrial output value.

\subsubsection{Model Construction}

Following Du and $\mathrm{Mu}$ [52] and He and Ma [53], this paper regarded the two industries as a composite industry system to construct the evaluation indicator system of CC and adopted the three-stage super-efficiency SBM model to establish the CC development's evaluation model.

In the first stage, the super-efficiency SBM model was used to deal with the undesirable output effectively, and DMUs whose efficiency scores exceeded one were distinguished accurately. In the super-efficiency SBM model proposed by Tone [36], the slack variable was placed in the objective function for the first time.

The stochastic frontier regression analysis model (SFA) was used in stage 2. The SFA model mainly solves the problem that DMU was disturbed by environmental factors in the first stage. In this stage, the slack variables were decomposed as three functions of environmental factors, random factors, and management factors, and a new input value excluding environmental factors and random errors was obtained and each DMU was in the same external environment. The SFA model is described as follows. 
The adjusted super-efficiency SBM model was used in stage 3. In this stage, the original input value of the first stage was replaced by the adjusted new input value, and the output value remained unchanged. Then, they were included in the super-efficiency SBM model for calculation, so as to obtain the more real and objective efficiency value of each DMU after eliminating the interference of environmental factors and random errors.

According to Cao and Deng [40], in the fractional planning of DEA model, if the numerator and denominator were input-output combinations of different industrial systems, the efficiency value calculated by the model represented the relative effectiveness of mutual promotion and reflected the state of the coordination and development among industries. In this paper, LIMI were regarded as input-output systems, and DEA was used to evaluate the CC development level's effectiveness of the two industries, that is, to evaluate the relative effectiveness of the mutual promotion between LIMI.

If the denominator represents the input portfolio of industry $\mathrm{A}$ and the numerator represents the output portfolio of industry $\mathrm{B}$, then $h_{e}\left(\frac{A}{B}\right)$ is used to represent the CC development level's effectiveness of industry A to industry B, which is calculated as:

$$
\begin{gathered}
\operatorname{minh} h_{e}(A / B) \\
\sum_{j=1}^{n} x_{A j} \gamma \frac{A}{B_{j}}+S^{-}=x_{A 0} h_{e 0}(A / B) \\
\text { s.t. } \sum_{j=1}^{n} y_{B j} \gamma_{A / B_{j}}-S^{+}=y_{B 0} \\
\delta \sum_{j=1}^{n} \gamma A / B_{j}=\delta \\
\gamma A / B_{j} \geq 0 \\
S^{-} \geq 0, S^{+} \geq 0, \delta=0 \text { or } 1
\end{gathered}
$$

Similarly, CC degree $h_{e}(A / B)$ can be calculated with industrial system B as the input and industrial system A as the output. The basic model of the DEA CC evaluation method was replaced by the three-stage super-efficiency SBM model based on undesirable output, and the calculated efficiency value is the effectiveness $h_{e}(A / B)$ and $h_{e}(B / A)$ of CC development. In Equation (1), $0 \leq h_{e}\left(\frac{A}{B}\right) \leq 1$. The closer $h_{e}(A / B)$ was to 1 , the more efficient the input of industrial system $A$ was to the output of industrial system $B$; namely, the more suitable the input-output relationship between industrial system $A$ and industrial system B was, and the better the CC effect of industrial system A on industrial system B was. Otherwise, the opposite held true.

The calculation formula of $h_{e}(A, B)$ of CC development level's comprehensive effectiveness in LIMI is as follows [49]:

$$
h_{e}(A, B)=\frac{\min \left\{h_{e}(A / B), h_{e}(B / A)\right\}}{\operatorname{Max}\left\{h_{e}(A / B), h_{e}(B / A)\right\}}
$$

To sum up, the calculation process is described in Figure 1, where $h_{e}(L / M), h_{e}(M / L)$ and $h_{e}(M, L)$, respectively, represent the relative effectiveness of LI in promoting the development of MI, the relative effectiveness of MI in promoting the development of LI, and the CC development level's comprehensive effectiveness in LIMI.

\subsubsection{Classification and Evaluation Standards of CC Degrees}

According to the classification standards by Hsiao et. al. [6], the CC degree is divided into three continuous ranges and ten subdivision types, which are used to represent the state and degree of CC development among industrial systems (see Table 2). 


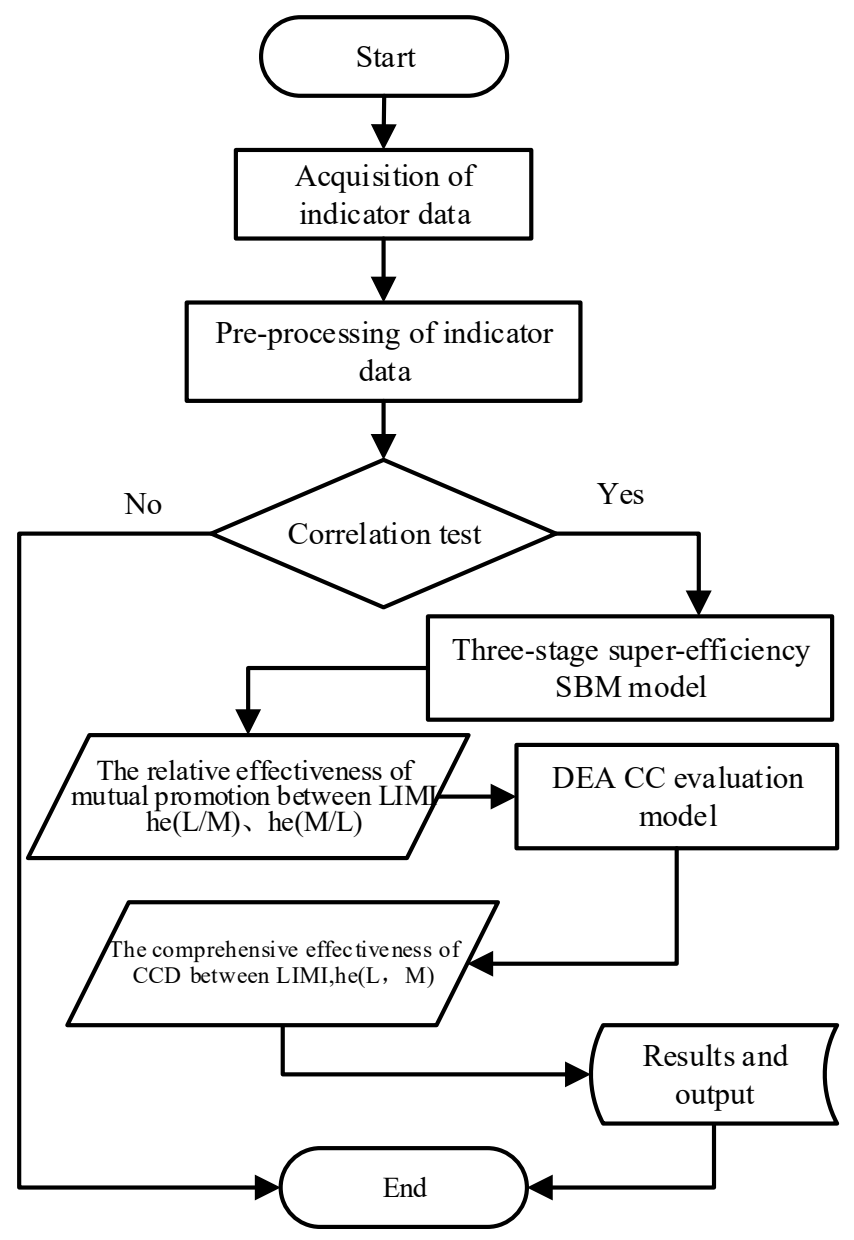

Figure 1. Calculation process of CC development level in LIMI.

Table 2. Classification standards of CC level.

\begin{tabular}{ccc}
\hline Range & CC Level & Type \\
\hline \multirow{3}{*}{ Unacceptable } & $0-0.09$ & Recession with extreme dysfunction (A1) \\
& $0.10-0.19$ & Recession with severe disorders (A2) \\
& $0.2-0.29$ & Recession with moderate disorders (A3) \\
& $0.3-0.39$ & Recession with mild disorders (A4) \\
\hline \multirow{2}{*}{ Transitional } & $0.4-0.49$ & Recession on the verge of disorders (B1) \\
& $0.5-0.59$ & Development with limited coordination (B2) \\
\hline \multirow{2}{*}{ Acceptable } & $0.6-0.69$ & Development with primary coordination (C1) \\
& $0.7-0.79$ & Development with intermediate coordination (C2) \\
& $0.8-0.89$ & Development with good coordination (C3) \\
$0.9-1$ & Development with higher coordination (C4) \\
\hline
\end{tabular}

\section{Results}

\subsection{Indicator Correlation Analysis}

In the DEA model, the input-output indicator variables should satisfy the hypothesis of "isotropy". The software SPSS was used to test the correlation of input-output indicator variables based on the Pearson correlation test method. The results are shown in Appendix Table A1. The correlation coefficients between the input and output variables have passed Pearson's bilateral test at the significance level of 5\%. This met the requirements of the model, indicating that the selection of indicators was reasonable. 


\subsection{Calculation Results of Three-Stage Super-Efficiency SBM Model}

Taking eleven provinces and cities of YREB as DMUs, this paper adopted the software DEA-SOLVER PRO 5.0 to process the indicator data. The evaluation results in the first stage (see Appendix Table A2) showed that, without considering environmental factors, random errors and management factors, the CC level of LIMI in YRBL varied greatly from region to region. In order to improve the accuracy of the results, SFA regression model was further used in the second stage (see Appendix Table A3), and all DMUs were placed in the same external environment. With the output indicator unchanged, the adjusted input indicator data in the second stage were incorporated into SBM model for calculation and the relative effectiveness of LIMI promoting each other could be respectively obtained.

On the whole, the relationship of mutual promotion between LIMI in YREB is significant. In the past ten years, YREB has gradually developed into a new highland of China's MI, and the increasing demand for logistics services has boosted the development of regional logistics industry. However, the role of LI in promoting MI is not significant, and a benign development mode of LI promoting MI has not yet been formed. Specifically, on the one hand, from 2007 to 2017, the average relative effectiveness of LI in promoting the development of MI in YREB was about 0.6 , and only $20 \%$ of the provinces realize the effectiveness annually. There exist large development differences among regions, and the overall distribution pattern is high in the east and low in the west. On the other hand, during the period of study, the average relative effectiveness of $\mathrm{MI}$ in promoting the development of $L I$ in YREB was about 1, and $40 \%$ of the provinces realize the effectiveness annually. This shows that MI plays a significant role in promoting the development of LI, but the overall distribution pattern is also high in the east and low in the west. Therefore, the improvement of logistics service in the middle and upper reaches of YREB is the key to turning YREB into a new support belt for China's MI, restructuring and upgrading MI in the lower reaches, and undertaking the industrial transfer of MI in the eastern coastal areas. In order to obtain a more significant result, this paper selected the data of 2007, 2013, and 2017 to compare and analyze the changes in the effectiveness of mutual promotion between LIMI before and after the adjustment.

(1) The effectiveness of LI in promoting the development of MI

After eliminating the interference of environmental factors, the CC level of LI to MI in YREB still maintained the overall distribution pattern of "high in the east and low in the west", and the spatial distribution was basically consistent, which indicated that MI was the main demander of the development of LI, and LI, as an input factor, was more directly transformed into the output of MI, and the influence of environmental factors and random errors on the relative effectiveness of LI in promoting the development of MI was small. As is shown in Figure 2, from the perspective of regional mean, after adjustment, the mean in the lower reaches was decreasing as a whole, which indicated that the relative effectiveness of LI in promoting MI in the lower reaches was overestimated in the first stage. The reason may be that the regions in the lower reaches of the Yangtze River were the most economically developed ones in China and their superior external environmental factors in economy, policy, science and technology, and transportation, and their advanced management had a positive impact on the input efficiency of regional LI, but after eliminating these favorable factors, the effectiveness of LI in promoting the development of MI had declined. However, the mean in the middle and upper reaches was increasing after adjustment, which indicated that the relative effectiveness of LI in promoting the development of $\mathrm{MI}$ in the middle and upper reaches was underestimated in the first stage. It implied that the external environmental factors in economy, policy, science and technology, and transportation, and their management level in the middle and upper reaches, restricted the improvement of the economic benefits of LI, but after eliminating the environmental factors and random interference, the effectiveness of LI in promoting the development of MI had improved. 


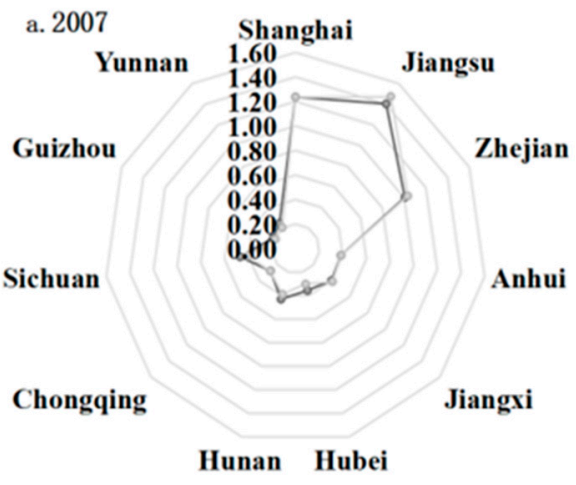

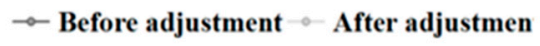

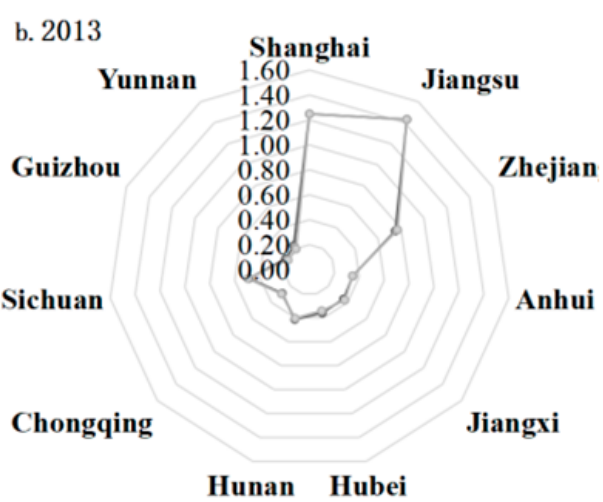

$\rightarrow$ Before adjustment $\rightarrow$ After adjustment

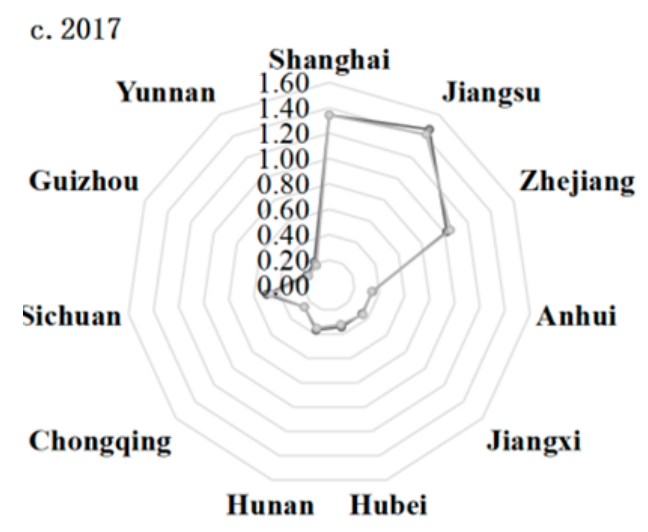

$\rightarrow$ Before adjustment $\rightarrow$ After adjustment

Figure 2. Comparison of coordination degree of LI to MI before and after adjustment.

(2) The effectiveness of MI in promoting the development of LI

It can be seen from Figure 3 that after adjustment, the relative effectiveness of MI in promoting the development of LI was basically consistent with the results in the first stage, with the overall distribution characteristics of "high in the east and low in the west", but with the increasing regional differences. Comparing Figure 2 with Figure 3, we found that the effectiveness of MI in promoting the development of LI had a greater change compared with the relative effectiveness of LI in promoting the development of MI, which indicated that the economic efficiency of MI was more sensitive to environmental factors. From the perspective of regional mean, after adjustment, the mean in the lower reaches was rising, while the mean in the middle and upper reaches was falling, which was just the reverse change with LI. The relative effectiveness in the lower reaches was underestimated in the first stage, which indicated that the industrial efficiency of MI was affected by the adverse external environment. At present, the service industries have become the leading industries in the lower reaches of the Yangtze River, while MI is facing the outward transfer of capacity and structural upgrading. Meanwhile, the in-depth development of urbanization also brings greater pressure on the urban ecological environment. Therefore, the existing external environment in the lower reaches restricts the improvement of MI efficiency, which makes the effectiveness in the lower reaches underestimated. On the contrary, in order to undertake the transfer of capacity of MI, regions in the middle and upper reaches actively introduce preferential policies for foreign investment and build industrial parks and innovation incubation bases, which, to a certain extent, provides a good external environment for the improvement of MI efficiency, making the effectiveness in the middle and upper reaches regions overestimated. 


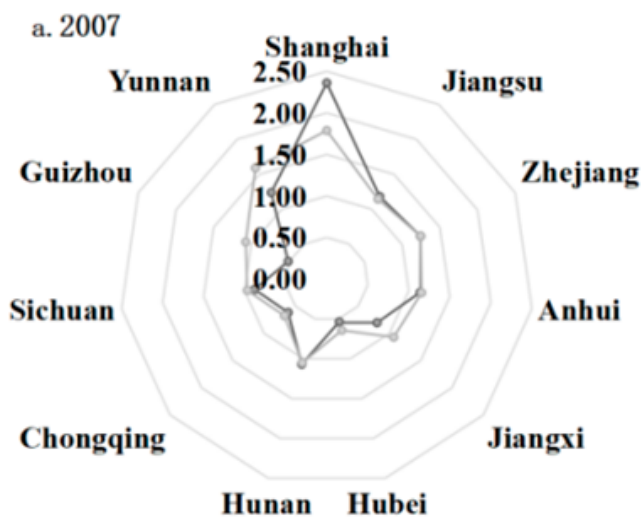

$\rightarrow$ Before adjustment $\rightarrow$ After adjustment

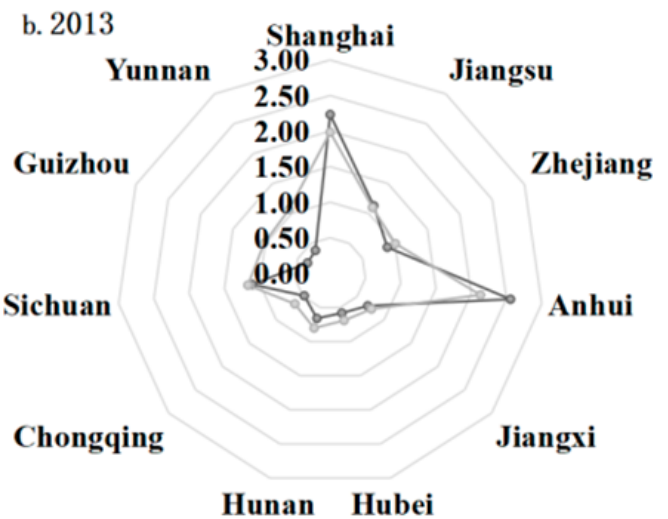

$\rightarrow$ Before adjustment $\rightarrow$ After adjustment

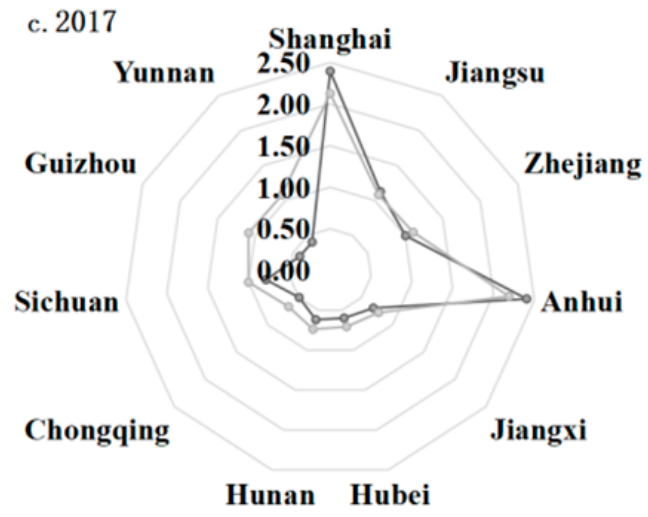

$\rightarrow$ Before adjustment $\rightarrow$ After adjustment

Figure 3. Comparison of coordination degree of MI to LI before and after adjustment.

\subsection{Calculation Results of DEA CC Evaluation Model}

\subsubsection{Measurement and Classification of CC Level}

With the help of the three-stage DEA model, the relative effectiveness of mutual promotion between LIMI could be measured respectively. Based on the CC evaluation model, the comprehensive effectiveness of the CC development in LIMI could be further obtained with the specific data and change trend shown in Figure 4. The value of comprehensive effectiveness reflected such comprehensive indicators in the two industrial systems as the internal structure, the allocation proportion of production factors, the input-output ratio, and the development scale. The higher the value was, the higher the CC levels in LIMI were, and the higher the degree of development synchronization was.

The results showed that, from 2007 to 2017, CC levels of LIMI in eleven provinces and cities of YREB remained stable as a whole. Except Jiangsu and Zhejiang in the stage of acceptable coordinated development and Anhui in the stage of disorder and recession, most provinces and cities were still in the transitional stage, which showed that the two industries were still in the running-in stage of limited coordination and had not yet reached the benign coupling. 


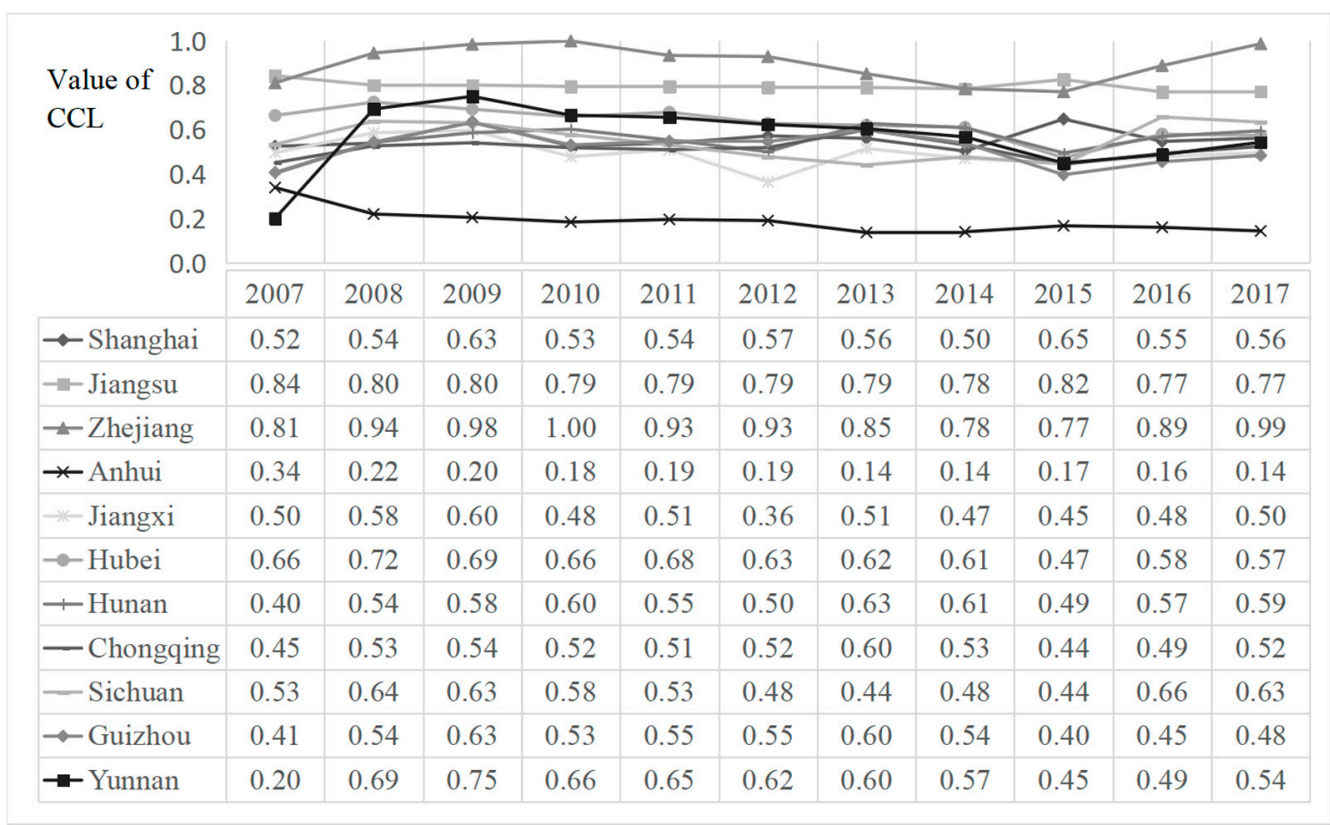

Figure 4. Comprehensive effectiveness of CC levels between LIMI in provinces and cities of YREB from 2007 to 2017.

\subsubsection{Spatio-Temporal Evolution of CC Levels}

Similarly, this paper selected three time nodes of the years 2007, 2013, and 2017 to analyze the spatio-temporal evolution characteristics of CC levels of LIMI in YREB from the regional and provincial levels.

(1) Spatio-temporal evolution of CC levels at the regional level

In order to further analyze the spatio-temporal evolution characteristics, the evolution trend of regional CC levels was first drawn (Figure 5) and then, with the help of the software Arc GIS, the CC level was divided into five main types to draw the spatial pattern evolution map (Figure 6). It can be seen from Figure 5 that the CC levels of the two industries, as a whole, presented the development pattern of "high in the east and low in the west", showing the evolution characteristics of being first rising and then falling, and experiencing the development process of "running-in-coordination-running-in". The possible reasons for the characteristics are as follows. Before and after 2009, the Chinese government successively issued a number of industrial revitalization policies, including Opinions on Promoting the Linkage Development of MI and LI (No. 32 in 2010 by National Development and Reform Commission), which have effectively promoted the coordinated development of the two industries. With the YREB Strategy proposed in 2013, transfer and diffusion of regional MI have been further accelerated. Especially in recent years, with the rapid development of the Internet economy, industrial transfer among cities has been more frequent. However, on the one hand, the cost of China's LI remains high, which makes it difficult to improve the profit. On the other hand, the average investment in the research and development of China's LI is far lower than that of MI, which leads to the underdevelopment of the logistics industry being the main factor restricting the coordination between the two industries. These conflicts have broken the coordination between LIMI in YREB, and the CC degree shows a fluctuating downward trend. Therefore, how to reduce the logistics cost and improve the service ability are extremely important to promote the CC development of the two industries. 


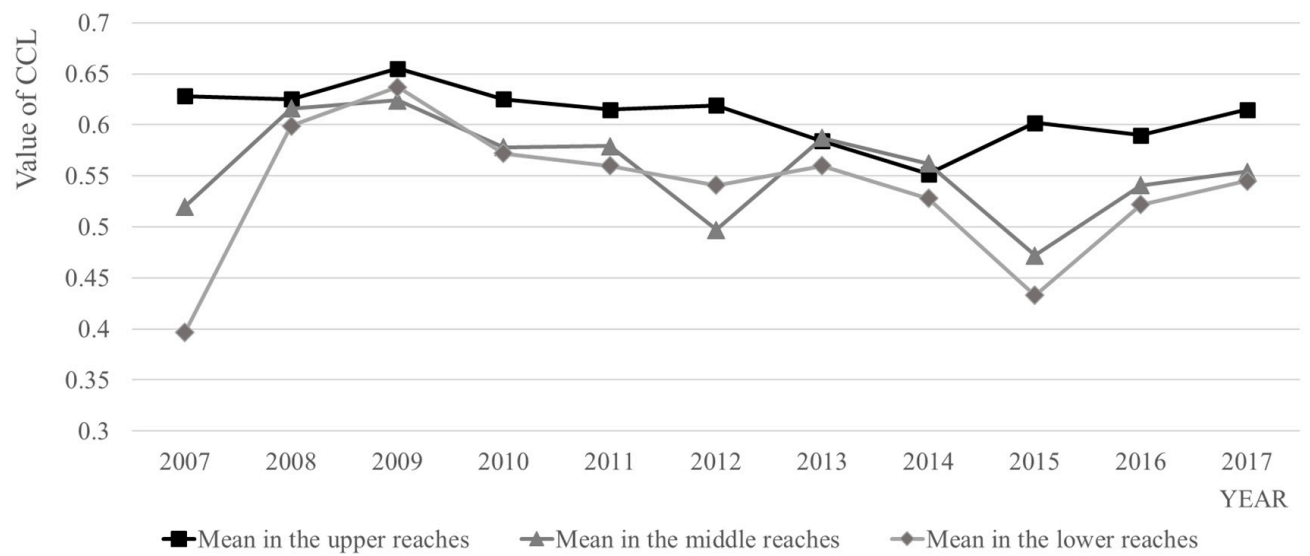

Figure 5. Evolution trend of the mean of CC levels in YREB.
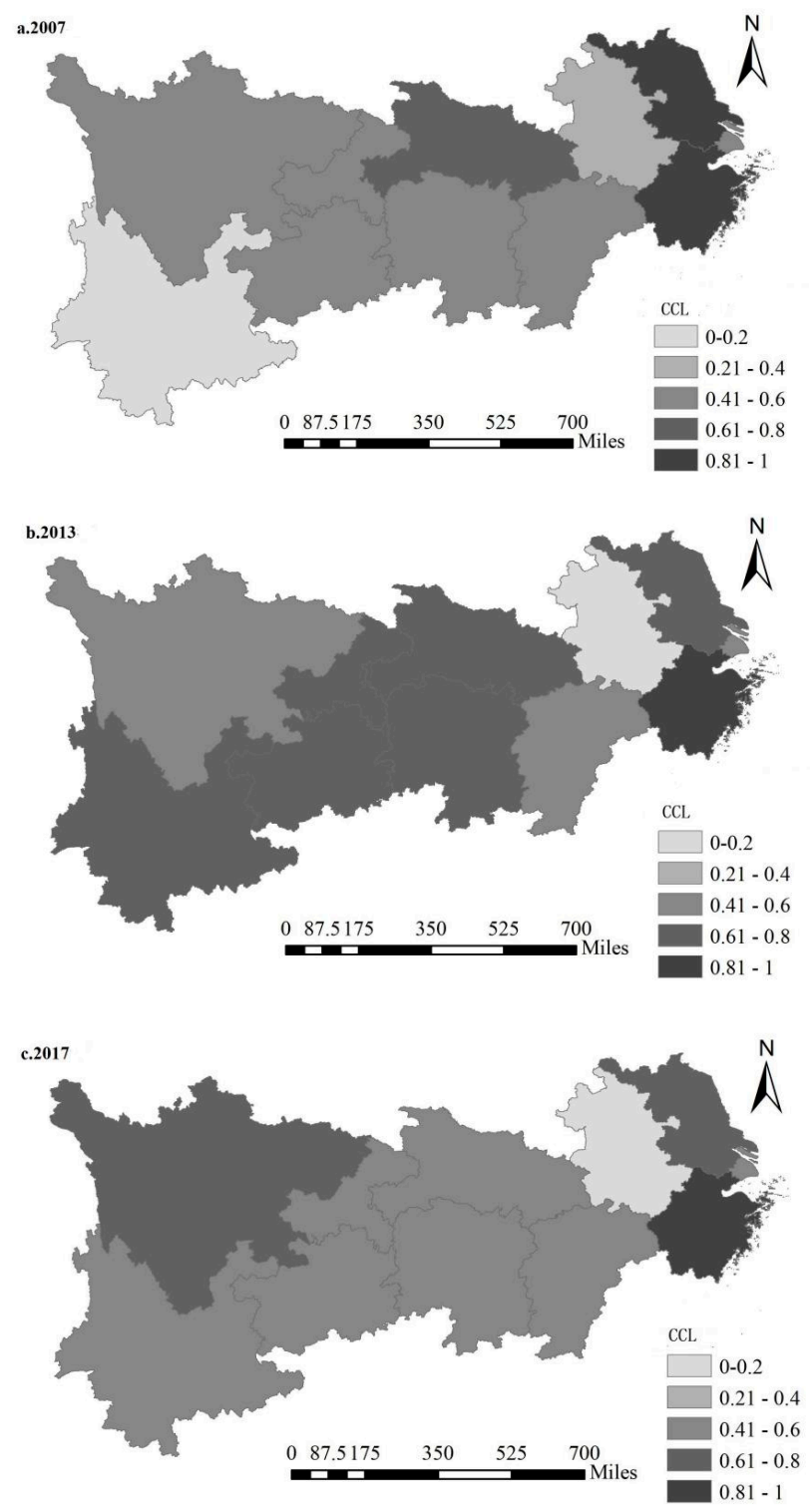

Figure 6. Spatial pattern evolution of CC degree between LIMI in YREB. 
It has been found that CC levels in the lower reaches are significantly higher than those in the middle and upper reaches and have been in the stage of primary coordination stage, with CC levels in Jiangsu and Zhejiang being obviously higher than those in other provinces and cities. The spatial distribution of CC levels among provinces is scattered with large differences between provinces. In 2007, as a whole, CC levels in the lower reaches belong to the coordinated development type in the acceptable range with relatively small differences in inter-provincial development. In 2013, the mean of regional CC levels declined to the limited coordination type in the transitional range, and the differences of CC development between provinces were further aggravated, gradually decreasing from Zhejiang to the surrounding areas. In 2017, the mean of CC levels in the lower reaches rebounded to the primary coordination stage in the acceptable range.

Overall, CC levels in the middle reaches are higher than those in the upper reaches, showing a rising trend of fluctuation and being maintained in the stage of limited coordination. The differences of CC levels among provinces are smaller, with the distribution characteristics of spatial agglomeration pattern. In 2007, CC levels in the middle reaches as a whole belonged to the limited coordination type in the transitional range, in which CC levels between LIMI in Hubei were the highest. By 2013, CC levels in the middle reaches were still in the transition range, but the whole CC level was improved. In 2017, CC levels of all the provinces were in the stage of limited coordination.

The mean of CC levels in the upper reaches is basically at the lowest value, but the overall evolution trend is basically consistent with that in the middle reaches, with the development characteristics of limited coordination-on the verge of imbalance-limited coordination, and meanwhile CC levels have certain characteristics of spatial agglomeration. Jiangsu and Zhejiang are major manufacturing provinces in China, and their oil refining, automobile, clothing, machinery, and other manufacturing industries have achieved a considerable scale. According to the latest data released by the All-China Federation of Industry and Commerce, 241 enterprises in the provinces and cities of YREB have been shortlisted in the top 500 of China's manufacturing enterprises in 2020. Among them, the total number of enterprises in Jiangsu, Zhejiang, and Shanghai accounts for $62 \%$, the number in the middle reaches $24 \%$, and that in the upper reaches only accounts for 14\%. As for LI, 207 enterprises in YREB have been shortlisted in the top 500 of China's service enterprises in 2020. Among them, there are only 10 logistics and transportation service enterprises which are mainly distributed in Sichuan and Chongqing, and the other e-commerce logistics service enterprises such as Jingdong, Shunfeng, and Shentong have very low participation in the supply chain of MI. These data further confirm the conclusion of this paper that the development of LI in YREB is still very slow and improving the service ability of LI and deeply participating in the supply chain system of MI are important measures to promote the $\mathrm{CC}$ of the two industries.

(2) Spatio-temporal evolution of CC level at the provincial level

According to Table 3, from the provincial perspective, since 2007, CC levels in Jiangsu and Zhejiang have been above the intermediate, indicating that the systems between LIMI in the two provinces maintain a coupling resonance state of mutual promotion and common development. The comprehensive effectiveness in Shanghai, Jiangxi, Hunan, Chongqing, Sichuan, and Guizhou is relatively stable and basically in the running-in stage. Among them, CC levels in Shanghai and Jiangxi were in the stage of limited coordination in 2007, 2013, and 2017; CC levels in Hunan and Chongqing show the development characteristics of on the verge of imbalance-primary coordination-limited coordination; the comprehensive effectiveness of CC in Sichuan declined from limited coordination in 2007 to on the verge of imbalance in 2013, but it broke 0.6 during the year 2016 and 2017, maintaining a good momentum of development to a higher stage; the CC level in Guizhou shows the characteristics of on the verge of imbalance-primary coordination-on the verge of imbalance; the CC level in Hubei shows a falling trend of fluctuation with the development characteristics of primary coordination-on the verge of imbalance-limited coordination; and the CC level in Yunnan shows a rising trend of fluctuation with the 
characteristics of intermediate coordination-primary coordination-limited coordination. It is generally shown in these provinces and cities that the input-output benefit of LI to MI is insufficient, and the economic efficiency of LI is low, which leads to the fact that the relative effectiveness of LI in promoting the development of MI lags behind that of MI in promoting the development of LI. Anhui is the only province in which the CC level is in imbalance recession of the unacceptable range with a falling trend of fluctuation from mild imbalance to serious imbalance. The relative effectiveness of MI in promoting the development of LI in Anhui is far behind that of LI in promoting the development of MI. The reason is that in the past, input in Anhui has been relatively excessive. Taking the year 2017 as an example, in LI in Anhui, the projection values of total social fixed asset investment, the employees' average salary, total energy consumption, and total industrial carbon emission were 14.232 billion yuan, 1972.531 billion yuan, 3.2657 million tons, and 11.6494 million tons, respectively, and the output of MI was insufficient. For instance, the projection values of total industrial output value in 2017 was 146.001 billion yuan. Therefore, the key is to improve the industrial economic efficiency of MI. In recent years, all provinces and cities in YREB have been facing the problem of transformation and upgrading of industrial structure. Therefore, the CC development of the two industries plays a significant role in creating new industrial economic growth points and avoiding industrial convergence.

Table 3. CC level and type in provinces and cities in YREB in 2007, 2013, and 2017.

\begin{tabular}{|c|c|c|c|c|c|c|}
\hline \multirow{2}{*}{ Provinces and Cities } & \multicolumn{2}{|c|}{2007} & \multicolumn{2}{|c|}{2013} & \multicolumn{2}{|c|}{2017} \\
\hline & CC Level & Type & CC Level & Type & CC Level & Type \\
\hline Shanghai & 0.52 & B2 & 0.56 & B2 & 0.56 & B2 \\
\hline Jiangsu & 0.84 & $\mathrm{~B} 2$ & 0.79 & $\mathrm{C} 2$ & 0.77 & $\mathrm{C} 2$ \\
\hline Zhejiang & 0.81 & C3 & 0.85 & C3 & 0.99 & $\mathrm{C} 4$ \\
\hline Anhui & 0.34 & A4 & 0.14 & $\mathrm{~A} 2$ & 0.14 & $\mathrm{~A} 2$ \\
\hline Jiangxi & 0.50 & $\mathrm{~B} 2$ & 0.51 & $\mathrm{~B} 2$ & 0.50 & B2 \\
\hline Hubei & 0.66 & $\mathrm{C} 1$ & 0.62 & C1 & 0.57 & B2 \\
\hline Hunan & 0.40 & B1 & 0.63 & C1 & 0.59 & B2 \\
\hline Chongqing & 0.45 & B1 & 0.60 & C1 & 0.52 & B2 \\
\hline Sichuan & 0.53 & B2 & 0.44 & B1 & 0.63 & $\mathrm{C} 1$ \\
\hline Guizhou & 0.41 & B1 & 0.60 & C1 & 0.48 & B1 \\
\hline Yunnan & 0.20 & A3 & 0.60 & C1 & 0.54 & B2 \\
\hline
\end{tabular}

\section{Implications}

Based on the above research results, the following implications were drawn in this paper. First, the participation of LI in supply chain cooperation should be strengthened to enhance the relative effectiveness of LI in promoting the development of MI. Overall, the CC development level of LIMI in YREB is still at the level of basic coordination during the transition and the LIMI have not yet reached a benign coupling state. The reason is that the relative effectiveness of LI in promoting the development of MI is still low, far lagging behind the relative effectiveness of MI in promoting the development of LI, resulting in the non-coordinated development of the two industries. The conclusion of this paper tends to be "supply-oriented theory", which recommends that on taking into account the leading and driving role of MI to LI, CC development of LIMI should be enhanced. LI also needs to deeply participate in supply chain cooperation to improve the latter's overall efficiency; the government should cultivate high-quality logistics enterprises to promote LI to achieve service extension and provide personalized services for MI, comprehensively improving the service of LI.

Second, the logistics development in the middle and upper reaches should be strengthened in order to break CC status quo of "high in the east and low in the west". On the whole, the CC development level of LIMI shows a spatio-temporal evolution trend of "high in the east and low in the west", with the lower reaches of the Yangtze River being the highest, the middle reaches following, and the upper reaches being the lowest, 
and experiences the evolution characteristics of "running-in-coordination-running-in". Meanwhile, the relatively backward development of LI has brought challenges for the middle and upper reaches to undertake the transfer of capacity of MI in the lower reaches. Therefore, the key points of government decision-making in the middle and upper reaches should focus on improving the level of environment and management factors in economy, policy, science, and technology, and enhancing the economic benefits of LI. The supply and demand planning of LI should be strengthened in the middle and upper reaches to promote the effective combination of LIMI. MI should be encouraged to implement logistics outsourcing and accelerate its own transformation and upgrading of its own MI, and improve the agglomeration quality of MI.

Third, the seamless transfer and undertaking of manufacturing industries in the upper and lower reaches should be promoted to improve the anti-interference ability of MI. The relative effectiveness of LI in promoting the development of MI is less affected by environmental factors and random factors. In comparison with the middle and upper reaches, more favorable environmental factors have been provided for the improvement of input efficiency of LI in the lower reaches. On the contrary, the relative effectiveness of MI in promoting the development of LI is more vulnerable to the interference of environmental factors and random factors. Compared with the middle and upper reaches, the environment in the lower reaches is more unfavorable to the development of MI. For a period of time to come, the policies in the lower reaches should focus on accelerating the outward transfer of excess capacity and structural upgrading of MI and promoting the rapid development of modern service industries such as logistics, and further promoting the integration of green manufacturing and green logistics. In the middle and upper reaches, policies should be formulated to actively undertake the transfer of capacity of MI, and meanwhile preferential policies for foreign investments should be introduced and industrial parks and innovation incubation bases should be created to provide a good external environment for the efficiency of MI.

Fourth, the formation of a new pattern of dual cycle development between China and the world should be promoted to boost CC development of the two industries since the improvement of regional economy and openness is conducive to the input efficiency of LIMI. Now, the increase of the government's fiscal investment in industry has promoted the expansion of industry and led to the waste of the factors of production. The scientific and technological innovation exerts no significant impact on the input of LI which causes the waste of input factors of MI, and the promotion and application of innovative technology in the two industries are not high. Therefore, the following policy suggestions are provided. First, it is recommended to construct a regional industrial cluster in MI supported by high-quality logistics, build a whole industry chain system with both internal and external circulation, and further expand the opening up. Second, the precise state of input-output elements should be found out to reduce "redundant" input and expand effective output. Third, the popularization and application of the new generation of information technology should be promoted to accelerate the transformation of innovation achievements and technology diffusion and enhance the independent innovation ability of enterprises. Fourth, the emerging service trade which is highly matched with MI should be expanded.

\section{Conclusions}

In view of the reality that LIMI in YREB promote mutual development with high quality, this paper used the three-stage super-efficiency SBM model based on undesirable output to conduct an empirical study on the CC development level of LIMI in YREB from the input-output perspective. The model eliminated the influence of environmental factors and random errors, making the calculation results more accurately and truly reflective of the spatio-temporal differences of CC development level of LIMI in different regions of YREB, which is the major theoretical contribution of our investigation. The main conclusions are as follows. 
First, on the whole, the CC development level of LIMI in YREB is still in the bare coordination level of the transitional range, and LIMI have not yet reached a benign coupling state. Second, the overall CC development level of LIMI has shown a spatiotemporal evolution trend of "high in the east and low in the west" with the lower reaches of the Yangtze River being the highest, the middle reaches following, and the upper reaches being the lowest, and has experienced the evolution characteristics of "runningin-coordination-running-in". Third, the development of LI in YREB is still slow, and the service ability of LI needs to be improved and deeply involved in the supply chain system of MI. The relatively backward development of LI has brought challenges for the middle and upper reaches to undertake the transfer of capacity of MI in the lower reaches.

The limits of this paper lie in the validity of the indicator system. First, there is a lack of statistical indicator data of LI in China. Therefore, on constructing the indicators, this paper, based on the summary and references of the existing literature, selected some representative indicators of such industries as transportation industry and warehousing industry as alternatives, which may not cover all of the indicators. Second, because of the difficulty in data collection, some indicators of MI have been replaced by the relevant ones of the second industry, which, to a certain extent, affects the accuracy of the results of the data. In the future, a more comprehensive system in evaluating the indicators should be established to measure the research results more accurately and scientifically so as to make the research conclusions more convincing.

Author Contributions: Conceptualization, Y.G. and Y.-F.Z.; methodology, Y.-F.Z.; software, C.-Y.R.; validation, X.-Q.Y. and C.-Y.R.; formal analysis, V.S.; investigation, Y.G.; writing-original draft preparation, C.-Y.R.; writing —review and editing, Y.-F.Z.; project administration, Y.G.; funding acquisition, Y.G. All authors have read and agreed to the published version of the manuscript.

Funding: This research was funded by the Opening Foundation of Research Center for Economy of Upper Reaches of the Yangtze River, grant number KFJJ2019004, and the Humanities and Social Sciences Planning Project of Ministry of Education, grant number 16YJAZH012.

Institutional Review Board Statement: Not applicable.

Informed Consent Statement: Informed consent was obtained from all subjects involved in the study.

Data Availability Statement: Not applicable.

Conflicts of Interest: The authors declare no conflict of interest.

\section{Appendix A}

Table A1. Pearson correlation test of input-output indicator variables.

\begin{tabular}{|c|c|c|c|c|c|c|c|c|c|c|c|}
\hline & Y1 & $\mathrm{Y} 2$ & Y3 & $\mathrm{Y} 4$ & Y5 & Y6 & Y7 & Y8 & Y9 & Y10 & Y11 \\
\hline $\mathrm{Y} 1$ & 1 & $0.692^{* *}$ & $0.854^{* *}$ & $0.561^{* *}$ & 0.196 * & 0.027 & 0.164 & $0.811^{* *}$ & -0.041 & $0.768^{* *}$ & $0.708^{* *}$ \\
\hline $\mathrm{Y} 2$ & $0.692^{* *}$ & 1 & 0.741 & $0.243^{* *}$ & 0.707 & $\begin{array}{c}-0.307 \\
* *\end{array}$ & 0.137 & $0.681^{* *}$ & $\begin{array}{c}-0.369 \\
* *\end{array}$ & $0.612^{* *}$ & $0.536^{* *}$ \\
\hline $\mathrm{Y} 3$ & $0.854^{* *}$ & 0.741 & 1 & $0.437^{* *}$ & $0.506^{* *}$ & 0.057 & 0.181 * & 0.984 & 0.028 & $0.774^{* *}$ & 0.65 \\
\hline $\mathrm{Y} 4$ & $0.561^{* *}$ & $0.243^{* *}$ & $0.437^{* *}$ & 1 & 0.126 & $0.469 * *$ & $0.410^{* *}$ & $0.387^{* *}$ & $0.406^{* *}$ & $0.833^{* *}$ & $0.925^{* *}$ \\
\hline Y5 & $0.196^{*}$ & $0.707^{* *}$ & $0.506^{* *}$ & 0.126 & 1 & -0.029 & $0.389^{* *}$ & $0.495^{* *}$ & -0.067 & $0.480^{* *}$ & 0.370 ** \\
\hline Y6 & 0.027 & $-0.307^{* *}$ & 0.057 & $0.469 * *$ & -0.029 & 1 & $0.403^{* *}$ & 0.133 & $0.956^{* *}$ & $0.297^{* *}$ & $0.333^{* *}$ \\
\hline Y7 & 0.164 & 0.137 & $0.181 *$ & $0.410^{* *}$ & $0.389^{* *}$ & $0.403^{* *}$ & 1 & 0.164 & $0.361^{* *}$ & $0.510^{* *}$ & $0.404^{* *}$ \\
\hline Y8 & $0.811^{* *}$ & $0.681^{* *}$ & $0.984^{* *}$ & $0.387^{* *}$ & $0.495^{* *}$ & 0.133 & 0.164 & 1 & 0.112 & $0.727^{* *}$ & $0.596^{* *}$ \\
\hline Y9 & -0.041 & $-0.369 *$ & 0.028 & $0.406^{* *}$ & -0.067 & $0.956^{* *}$ & $0.361^{* *}$ & 0.112 & 1 & 0.231 * & $0.264^{* *}$ \\
\hline Y10 & $0.768^{* *}$ & $0.612^{* *}$ & $0.774^{* *}$ & $0.833^{* *}$ & $0.480^{* *}$ & $0.297^{* *}$ & $0.510^{* *}$ & $0.727^{* *}$ & $0.231 *$ & 1 & $0.942 * *$ \\
\hline Y11 & $0.708^{* *}$ & $0.536^{* *}$ & $0.652 * *$ & $0.925^{* *}$ & $0.370^{* *}$ & $0.333^{* *}$ & $0.404^{* *}$ & $0.596^{* *}$ & $0.264^{* *}$ & $0.942^{* *}$ & 1 \\
\hline
\end{tabular}

Note: **. The correlation is significant at the 0.01 level (two-tailed test); *. The correlation is significant at the 0.01 level (two-tailed test). 
Table A2. Relative effectiveness of LI in promoting the development of MI in stage 1.

\begin{tabular}{ccccccccccccc}
\hline No. & DMU & $\mathbf{2 0 0 7}$ & $\mathbf{2 0 0 8}$ & $\mathbf{2 0 0 9}$ & $\mathbf{2 0 1 0}$ & $\mathbf{2 0 1 1}$ & $\mathbf{2 0 1 2}$ & $\mathbf{2 0 1 3}$ & $\mathbf{2 0 1 4}$ & $\mathbf{2 0 1 5}$ & $\mathbf{2 0 1 6}$ & $\mathbf{2 0 1 7}$ \\
\hline 1 & Shanghai & 1.237 & 1.315 & 1.259 & 1.214 & 1.237 & 1.288 & 1.248 & 1.199 & 1.08 & 1.32 & 1.344 \\
2 & Jiangsu & 1.476 & 1.461 & 1.457 & 1.442 & 1.45 & 1.44 & 1.431 & 1.425 & 1.425 & 1.416 & 1.415 \\
3 & Zhejiang & 1.034 & 1.001 & 1.004 & 1.023 & 1.033 & 1.006 & 0.769 & 0.749 & 0.751 & 1.025 & 1.05 \\
4 & Anhui & 0.386 & 0.429 & 0.423 & 0.405 & 0.393 & 0.347 & 0.345 & 0.34 & 0.344 & 0.346 & 0.338 \\
5 & Jiangxi & 0.41 & 0.462 & 0.463 & 0.357 & 0.414 & 0.398 & 0.372 & 0.367 & 0.358 & 0.361 & 0.351 \\
6 & Hubei & 0.301 & 0.33 & 0.324 & 0.323 & 0.309 & 0.305 & 0.342 & 0.339 & 0.345 & 0.327 & 0.321 \\
7 & Hunan & 0.388 & 0.425 & 0.397 & 0.379 & 0.396 & 0.393 & 0.405 & 0.393 & 0.38 & 0.367 & 0.351 \\
$8 \quad$ Chongqing & 0.279 & 0.275 & 0.273 & 0.288 & 0.285 & 0.278 & 0.295 & 0.297 & 0.285 & 0.262 & 0.261 \\
$9 \quad$ Sichuan & 0.402 & 0.396 & 0.373 & 0.406 & 0.434 & 0.425 & 0.496 & 0.471 & 0.477 & 0.496 & 0.467 \\
$10 \quad$ Guizhou & 0.185 & 0.195 & 0.185 & 0.182 & 0.176 & 0.161 & 0.187 & 0.186 & 0.175 & 0.174 & 0.179 \\
$11 \quad$ Yunnan & 0.204 & 0.23 & 0.212 & 0.204 & 0.204 & 0.195 & 0.197 & 0.189 & 0.196 & 0.191 & 0.187 \\
Mean of upper & 1.033 & 1.052 & 1.036 & 1.021 & 1.028 & 1.020 & 0.948 & 0.928 & 0.900 & 1.027 & 1.037 \\
$\quad$ reaches & & & & & & & & & \\
$\begin{array}{c}\text { Mean of middle } \\
\quad \text { reaches }\end{array}$ & 0.366 & 0.406 & 0.395 & 0.353 & 0.373 & 0.365 & 0.373 & 0.366 & 0.361 & 0.352 & 0.341 \\
$\begin{array}{c}\text { Mean of lower } \\
\text { reaches }\end{array}$ & 0.268 & 0.274 & 0.261 & 0.270 & 0.275 & 0.265 & 0.294 & 0.286 & 0.283 & 0.281 & 0.274 \\
\hline
\end{tabular}

Table A3. Relative effectiveness of MI in promoting the development of LI in stage 1.

\begin{tabular}{|c|c|c|c|c|c|c|c|c|c|c|c|c|}
\hline No. & DMU & 2007 & 2008 & 2009 & 2010 & 2011 & 2012 & 2013 & 2014 & 2015 & 2016 & 2017 \\
\hline 1 & Shanghai & 1.789 & 2.051 & 1.99 & 1.943 & 1.958 & 2.042 & 1.984 & 1.939 & 1.603 & 1.949 & 2.128 \\
\hline 2 & Jiangsu & 1.144 & 1.117 & 1.114 & 1.103 & 1.117 & 1.107 & 1.099 & 1.092 & 1.096 & 1.084 & 1.082 \\
\hline 3 & Zhejiang & 1.244 & 1.007 & 1.009 & 1.043 & 1.031 & 1.014 & 1.006 & 1.014 & 1.044 & 1.062 & 1.106 \\
\hline 4 & Anhui & 1.156 & 1.794 & 1.814 & 1.728 & 1.815 & 1.731 & 2.132 & 2.225 & 1.909 & 2.044 & 2.19 \\
\hline 5 & Jiangxi & 1.069 & 1.026 & 1.043 & 0.842 & 0.886 & 1.025 & 0.766 & 0.784 & 0.768 & 0.792 & 0.775 \\
\hline 6 & Hubei & 0.644 & 0.626 & 0.644 & 0.63 & 0.58 & 0.603 & 0.691 & 0.686 & 0.806 & 0.69 & 0.706 \\
\hline 7 & Hunan & 1.051 & 1.051 & 1.022 & 0.903 & 1.008 & 1.03 & 0.802 & 0.784 & 1.017 & 0.777 & 0.738 \\
\hline 8 & Chongqing & 0.675 & 0.67 & 0.685 & 0.712 & 0.699 & 0.672 & 0.656 & 0.685 & 0.774 & 0.657 & 0.666 \\
\hline 9 & Sichuan & 0.968 & 0.823 & 0.773 & 0.875 & 1.006 & 1.032 & 1.167 & 1.058 & 1.115 & 0.945 & 1 \\
\hline 10 & Guizhou & 1.074 & 1.05 & 1.056 & 1.063 & 1.049 & 1.031 & 1.019 & 1.062 & 1.062 & 1.057 & 1.085 \\
\hline 11 & Yunnan & 1.591 & 1.049 & 1.041 & 1.036 & 1.042 & 1.04 & 1.067 & 1.05 & 1.073 & 1.074 & 1.08 \\
\hline \multicolumn{2}{|c|}{$\begin{array}{l}\text { Mean of upper } \\
\text { reaches }\end{array}$} & 1.077 & 0.898 & 0.889 & 0.922 & 0.949 & 0.944 & 0.977 & 0.964 & 1.006 & 0.933 & 0.958 \\
\hline \multicolumn{2}{|c|}{$\begin{array}{c}\text { Mean of middle } \\
\text { reaches }\end{array}$} & 0.921 & 0.901 & 0.903 & 0.792 & 0.825 & 0.886 & 0.753 & 0.751 & 0.864 & 0.753 & 0.740 \\
\hline \multicolumn{2}{|c|}{$\begin{array}{l}\text { Mean of lower } \\
\text { reaches }\end{array}$} & 1.333 & 1.492 & 1.482 & 1.454 & 1.480 & 1.474 & 1.555 & 1.568 & 1.413 & 1.535 & 1.627 \\
\hline
\end{tabular}

\section{References}

1. Zou, L.; Zhu, Y.-W. Research on Innovation Performance in Heterogeneous Region: Evidence from Yangtze Economic Belt in China. Complexity 2020, 2020, 8659134. [CrossRef]

2. Cohen, J.P. The broader effects of transportation infrastructure: Spatial econometrics and productivity approaches. Transp. Res. Part E Logist. Transp. Rev. 2010, 46, 317-326. [CrossRef]

3. Zhang, H.; Han, A.H. Can the coupling between manufacturing and productive services enhance spatial coordination-A test based on data from 285 cities in China. Stat. Res. 2019, 36, 39-50.

4. Jian, J.; Li, B.; Zhang, N.; Su, J. Decision-making and coordination of green closed-loop supply chain with fairness concern. J. Clean. Prod. 2021, 298, 126779. [CrossRef]

5. Murali, S.; Ching, N.Y. Study on producer logistics services and its outsourcing from manufacturing firms: A perspective of industrial cluster. Int. J. Phys. Distrib. Logist. Manag. 2010, 2, 524-527.

6. Hsiao, H.; Kemp, R.; Van Der Vorst, J.; Omta, S. (Onno) A classification of logistic outsourcing levels and their impact on service performance: Evidence from the food processing industry. Int. J. Prod. Econ. 2010, 124, 75-86. [CrossRef]

7. Hildegunn, N.; Yunhee, K. The Role of Services for Competitiveness in Manufacturing; OECD Publishing: Paris, France, 2013; pp. 23-30.

8. Bo, G.Z.; Li, S.Q. Coupling coordination between manufacturing industry and logistics industry in Pan Pearl River Delta. Henan Sci. 2014, 32, 1360-1363.

9. Lin, J. Analysis of interactive development mechanism and coupling coordinative degree between manufacturing and logistics industry in Fujian province. J. Fujian Jiangxia Univ. 2017, 7, 23-31. 
10. Long, X.; Ge, J.; Shu, T.; Liu, C. Production Decision and Coordination Mechanism of Socially Responsible Closed-Loop Supply Chain. Complexity 2020, 2020, 9095215. [CrossRef]

11. Zhong, Y.; Guo, F.; Tang, H.; Chen, X. Research on Coordination Complexity of E-Commerce Logistics Service Supply Chain. Complexity 2020, 2020, 7031543. [CrossRef]

12. Fried, H.O.; Lovell, C.A.K.; Schmidt, S.S.; Yaisawarng, S. Accounting for Environmental Effects and Statistical Noise in Data Envelopment Analysis. J. Prod. Anal. 2002, 17, 157-174. [CrossRef]

13. Wang, Y.; Zhou, G. Interaction mechanism between the logistics industry and manufacturing industry-Based on the perspective of different linkage types. IEEE Access 2021, 9, 1. [CrossRef]

14. Sohail, M.S.; Sohal, A.S. The Use of Third Party Logistics Services: A Malaysian Perspective. SSRN Electron. J. 2003, 23, 401-408. [CrossRef]

15. Rahman, S.; Yang, Y.; Xiaoyan, Y. Skill Requirements for Logistics Professionals in China: An Importance- Expertise Matrix Analysis. Supply Chain Forum Int. J. 2012, 13, 40-52. [CrossRef]

16. Khan, S.A.R.; Dong, Q.L.; Zhang, Y. Study of Logistics and Manufacturing Industry Integration from the Perspective of Pakistan. Int. J. Eng. Res. Afr. 2016, 24, 172-180. [CrossRef]

17. Guerrieri, P.; Meliciani, V. International Competitiveness in Producer Services. SSRN Electron. J. 2004, 122-131. [CrossRef]

18. Gong, X.W.; Wang, Y. Analysis of temporal and spatial evolution of coupling coordination between manufacturing and logistics Industry in China. J. Tech. Econ. Manag. 2016, 7, 8-12.

19. Shi, S.S. The Study on Coordinated Development of Productive Service Industry and Manufacturing Industry of Hebei; Inner Mongolia Normal University: Inner Mongolia, China, 2018.

20. Shen, L. Research on Economical Mechanism and Influencing Factors of Linkage Development between Manufacturing and Logistics Industry; Chang'an University: Xi'an, China, 2015.

21. Chen, C.M.; Chen, J.X.; Gu, J. Research on the evolution of the linkage development between manufacturing industry and logistics industry in China. J. Shandong Univ. 2020, 48, 73-81.

22. Tao, L. Research on the Linkage Development between Manufacturing Industry and Logistics Industry in Shaanxi Province from the Perspective of Sub-Industry Segmentation; Chang'an University: Xi'an, China, 2019.

23. Sun, P. A Study on Cooperative Development between Modern Logistics Service and Manufacturing Industry Based on Complex System Theory; Central South University: Hunan, China, 2012.

24. Li, C.; Bai, Y.; Xiang, X.; Xie, X. To mine coordinated development degrees of high-tech equipment manufacturing industry and logistics industry via an improved grey hierarchy analysis model. J. Grey Syst. 2017, 29, 105-119.

25. Gao, Y.; Chang, D.; Fang, T.; Luo, T. The Correlation between Logistics Industry and Other Industries: An Evaluation of the Empirical Evidence from China. Asian J. Shipp. Logist. 2018, 34, 27-32. [CrossRef]

26. Gong, X.W. Coordinated evolution and development trend between logistics and manufacturing industry. Ind. Eng. Manag. 2017, $22,140-146$.

27. Zhu, L. Coordination optimization model of manufacturing industry and logistics industry based on the hypernetwork. Syst. Eng. 2011, 29, 100-105.

28. Su, T.Y.; Zhang, L.L.; Zhao, X. The impact of the coupling of manufacturing industry and logistics industry on the productivity of manufacturing enterprises-Based on the perspective of industrial symbiosis. Ind. Eng. Manag. 2020, 25, 42-49.

29. Cheng, Y.W.; Gong, Y. A study on the interactive development of logistics industry in China. J. Beijing Jiao Tong Univ. 2014, 13, 1-7.

30. Bao, Y. Analysis on the Efficiency of Manufacturing Industry and Logistics Industry Combined Development in Anhui Province; Hefei University of Technology: Hefei, China, 2019.

31. Song, Q.; Zhou, N.; Liu, T.; Siehr, S.A.; Qi, Y. Investigation of a "coupling model" of coordination between low-carbon development and urbanization in China. Energy Policy 2018, 121, 346-354. [CrossRef]

32. Li, C.; Gao, X.; He, B.-J.; Wu, J.; Wu, K. Coupling Coordination Relationships between Urban-industrial Land Use Efficiency and Accessibility of Highway Networks: Evidence from Beijing-Tianjin-Hebei Urban Agglomeration, China. Sustainability 2019, 11, 1446. [CrossRef]

33. Wang, Q.; Mao, Z.; Xian, L.; Liang, Z. A study on the coupling coordination between tourism and the low-carbon city. Asia Pac. J. Tour. Res. 2019, 24, 550-562. [CrossRef]

34. Tang, Z. An integrated approach to evaluating the coupling coordination between tourism and the environment. Tour. Manag. 2015, 46, 11-19. [CrossRef]

35. Du, Y.W.; Liu, D.H. Coordination between the development of China's urbanization and service industry. Urban Probl. $2015,52-61$.

36. Tone, K. A slacks-based measure of super-efficiency in data envelopment analysis. Eur. J. Oper. Res. 2002, 143, 32-41. [CrossRef]

37. Fan, J.P.; Xiao, H.; Fan, X.H. A modified three-stage DEA model with undesirable output consideration-An empirical analysis based on Chinese provincial logistics efficiency. Chin. J. Manag. Sci. 2017, 25, 166-174.

38. Tang, J.R.; Du, J.J.; Tang, Y.C. Regional logistics efficiency evaluation and convergence study. J. Ind. Technol. Econ. 2018, 37, 61-70.

39. Mei, G.P.; Gong, Y.L.; Wan, J.X.; Ji, K.W. Study of the efficiency measurement of logistics industry in East China based on three-stage DEA model. Manag. Rev. 2019, 31, 234-241.

40. Cao, B.R.; Deng, L.J. Influencing factors of logistics industry growth efficiency in Yangtze River Economic Belt. Econ. Geogr. 2019, 39, 148-157. 
41. Tian, Z.; Cheng, F. Research on the production efficiency of equipment manufacturing industry in the East coastal areas of China-Based on three-stage DEA model. J. Ind. Technol. Econ. 2017, 36, 13-20.

42. Cheng, Z.L.; Zhao, W.G.; Li, J.K. Research on energy congestion effects in China's manufacturing sector: An analysis based on RA M-DEA. Syst. Eng. Theory Pract. 2019, 39, 1831-1844.

43. Ren, S.G.; Zhang, R.B.; Yuan, B.L. Industrial eco-efficiency evaluation and regional differences of Yangtze River Economic Belt. Acta Ecol. Sin. 2018, 38, 5485-5497.

44. Werner, M.J.E.; Yamada, A.P.L.; Domingos, E.G.N.; Leite, L.R.; Pereira, C.R. Exploring Organizational Resilience Through Key Performance Indicators. J. Ind. Prod. Eng. 2021, 38, 51-65. [CrossRef]

45. Slam, S.; Moeinzadeh, S.; Tseng, M.-L.; Tan, K. A literature review on environmental concerns in logistics: Trends and future challenges. Int. J. Logist. Res. Appl. 2021, 24, 126-151. [CrossRef]

46. Liu, B.L.; Yu, Y.Z. An empirical analysis on the regional disparity of efficiency and factor in China's logistics-Based on DEA and Tobit model. China Bus. Mark. 2010, 24, 18-21.

47. Zhao, Y.; Li, J. Study of the spatial efficiency of logistics industry agglomeration and its regional disparities in China. Econ. Probl. 2016, 65-70.

48. Zhou, Y.F.; Zou, T.G.; Liu, C.S.; Yu, H.; Chen, L.; Su, J. Blood supply chain operation considering lifetime and transshipment under uncertain environment. Appl. Soft Comput. 2021, 106, 107364. [CrossRef]

49. Liu, C.; Gong, Z.; Teo, K.L.; Sun, J.; Caccetta, L. Robust multi-objective optimal switching control arising in 1,3-propanediol microbial fed-batch process. Nonlinear Anal. Hybrid Syst. 2017, 25, 1-20. [CrossRef]

50. Zhou, Y.; Zheng, B.; Su, J.; Li, Y. The joint location-transportation model based on grey bi-level programming for early postearthquake relief. J. Ind. Manag. Optim. 2020, 13. [CrossRef]

51. Song, J.Z.; Chen, C.; Wang, X.P.; Hu, Z. Research on construction industry carbon emission efficiency based on three-stage super-efficiency DEA model. Environ. Sci. Technol. 2019, 42, 193-200.

52. Du, Z.P.; Mu, D. A study on DEA evaluation for synergetic development of system. Oper. Res. Manag. Sci. 2005, 75-81.

53. Yu-de, H.E.; Zu-jun, M.A. Study on CRITIC-DEA for regional logistics and regional economic coordinated development model and evaluation-A case study of Sichuan province. Soft Sci. 2015, 29, 102-106. 